\title{
Consumo, digestibilidade de nutrientes e parâmetros sanguíneos de cabras mestiças moxotó suplementadas com óleos de licuri ou mamona
}

\author{
Intake, digestibility of nutrients and blood parameters of crossbred moxotó goats suplemented \\ with licuri or castor oils
}

\author{
Michelle de Oliveira Maia' ${ }^{\mathrm{I}}$ Rita Cássia Ramos do Egypto Queiroga ${ }^{\mathrm{II}}$ Ariosvaldo Nunes de Medeiros ${ }^{\mathrm{III}}$ \\ Roberto Germano Costa ${ }^{\text {IV }}$ Marco Aurélio Delmondes Bomfim ${ }^{\text {V }}$ Marcelo Ferreira Fernandes $^{\text {III }}$
}

RESUMO

Objetivou-se com esta pesquisa avaliar a possibilidade da inclusão dos óleos de Licuri ou Mamona, em dois níveis, na dieta de cabras mestiças Moxotó, por meio do estudo do consumo de matéria seca, da digestibilidade e dos níveis de ureia, glicose e ácidos graxos não esterificados (AGNE) no sangue. Os tratamentos consistiam em um grupo controle sem óleo (SO) e adição de 3 ou 5\% de óleo de Licuri (OL-3 ou OL-5) ou Mamona (OM-3 ou OM-5), com base na matéria seca. Foram utilizadas 10 cabras mestiças Moxotó em lactação, confinadas, distribuídas em um quadrado latino duplo (5 x 5), no qual cada período consistia em 12 dias de adaptação e três dias de coleta. A inclusão de óleo na dieta reduziu o consumo de matéria seca, com exceção do consumo dos animais suplementados com OM-3. No entanto, a adição de $3 \%$ de óleo não alterou o consumo de energia metabolizável e proteína bruta. Já a suplementação com OL-5 reduziu o consumo dos nutrientes, com exceção do consumo de extrato etéreo. A suplementação lipídica não alterou a digestibilidade da matéria seca, entretanto aumentou a digestibilidade da FDN e a digestibilidade aparente da PB e EE. Os níveis de glicose, ureia e AGNE sanguíneos não diferiram entre os tratamentos. É possível utilizar 3\% de óleo de Mamona na dieta de cabras em lactação.

Palavras-chave: alimentação, caprinos, dieta, lipídeos.

\section{ABSTRACT}

The objective of this research was to evaluate the possibility of including Castor or Licuri oil at two levels in the diets of crossbred Moxotó goat's through dry matter intake, digestibility and levels of urea, glucose and nonesterified fatty acids (NEFA) in the blood. The treatments consisted of control groups without oil, $3 \%$ or $5 \%$ of Licuri (LO-3 or LO-5) or Castor (CO-3 or CO-5) oil, based on dry matter supplementation. Ten Moxotó lactating goats were used according to a double Latin Square $(5 \times 5)$ experiment design. The addition of oil to the diet reduced the dry matter intake, except for animals that were supplemented with $\mathrm{CO}-3$. However, the addition of $3 \%$ of oil didn't alter the intake of metabolizable energy and crude protein. The animals supplemented with $\mathrm{LO}$ 5 oil showed smaller nutrients intake, except for ether extract intake. The lipid supplement didn't alter the dry matter digestibility, however increased the NDF digestibility the CP and EE apparent digestibility. There was no difference among the glucose levels, urea and NEFA in the blood. It is possible to use $3 \%$ Castor oil in the diet of lactating goats.

Key words: diet, feeding, goat, lipids.

\section{INTRODUÇÃO}

Os lipídeos estão presentes normalmente na dieta de ruminantes, na forma esterificada como mono e digalactoglicerídeos em forragens e como triacilgliceróis em alimentos concentrados (OLIVEIRA et al., 2004). Podem ainda ser adicionados à dieta, na forma de óleos vegetais, visando a atender as exigências nutricionais, já que possuem maior valor energético do que qualquer outro nutriente, além de representarem a fonte de reserva energética mais importante para os animais (NRC, 2007).

'Departamento de Zootecnia, Escola Superior de Agricultura "Luiz de Queiroz" (ESALQ), Universidade de São Paulo (USP). Av. Pádua Dias, 11, CP 9, 13418-900, Piracicaba, SP, Brasil. E-mail: michellemrn@ig.com.br. Autor para correspondência. "Departamento de Nutrição, Centro de Ciências da Saúde (CCS), Universidade Federal da Paraíba (UFPB), João Pessoa, PB, Brasil. "IIDepartamento de Zootecnia, Centro de Ciências Agrárias (CCA), UFPB, Areia, PB, Brasil.

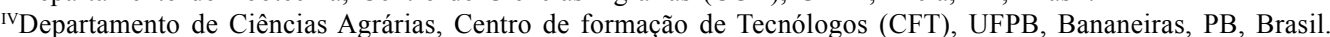

EMBRAPA caprinos, Sobral, CE, Brasil. 
A região Nordeste apresenta um grande potencial produtivo de óleos vegetais, o que deve ser mais explorado, principalmente, na região semiárida. Dentre os óleos existentes, o de Licuri e o de Mamona despertam interesse, pela ampla aplicabilidade.

O Licuri (Syagrus coronata) é uma das principais palmeiras da região semiárida do Nordeste brasileiro, sendo bem adaptada às regiões da caatinga e possui grande potencial alimentício, ornamental e forrageiro. No entanto, essa cultura ainda é explorada de forma extrativista. Segundo CREPALDI et al. (2001), na análise nutricional dos frutos do Licuri, merece destaque o teor de lipídeos (49,2\%) da polpa dos frutos.

A cultura da Mamona (Ricinus communis

L.) tem se mostrado altamente promissora na região Nordeste do Brasil, por sua fácil adaptação. Segundo VIEIRA et al. (1998), o teor de óleo das sementes de Mamona pode variar de 35 a $55 \%$. Após o processo de prensagem para extração do óleo, é originado um resíduo, conhecido como torta, a qual possui um alto teor de proteína (42\%), o que a torna muito atraente para a alimentação animal. No entanto, a presença de princípios tóxicos e alergênicos tem tornado inviável essa alternativa. As características antinutricionais se devem a três fatores: a proteína ricina, a ricinina e o complexo alergênico CB-1A (SEVERINO, 2005). Já o óleo de Mamona não possui ricina, pois toda a proteína da semente permanece na torta após o processo de extração.

Por ser escasso ou inexistente na literatura e devido suas ocorrências no Nordeste brasileiro, se torna importante o conhecimento dos efeitos desses óleos na alimentação animal. Por isso, objetivou-se avaliar a possibilidade da inclusão dos óleos de Licuri ou Mamona em dois níveis na dieta de cabras leiteiras mestiças Moxotó por meio do estudo do consumo e da digestibilidade dos nutrientes, além dos níveis sanguíneos de ureia, glicose e ácidos graxos não esterificados.

\section{MATERIAL E MÉTODOS}

O experimento foi realizado na Unidade de Pesquisa em Pequenos Ruminantes da Universidade Federal da Paraíba entre os meses de novembro de 2006 e janeiro de 2007. Foram utilizadas 10 cabras mestiças Moxotó, com peso vivo médio de $40 \pm 4,5 \mathrm{~kg}$

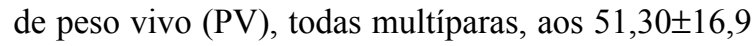
dias de lactação.

$\mathrm{O}$ ensaio com as dietas experimentais teve uma duração de 75 dias, composto de cinco períodos de 15 dias. Os primeiros 12 dias de cada período foram utilizados para adaptação dos animais às dietas experimentais, e os três dias seguintes foram destinados à coleta de dados. Os animais foram mantidos em regime de confinamento em baias individuais providas de comedouro e bebedouro, com água à vontade. Avaliaram-se rações completas (Tabela 1), com adição de dois tipos de óleos vegetais (Licuri ou Mamona) em dois níveis (3\% ou 5\%), com base na matéria seca (MS), formuladas segundo recomendações do NRC (1981).

A alimentação foi fornecida em duas refeições diárias às $7 \mathrm{~h}$ e $15 \mathrm{~h}$. Trabalhou-se com uma margem de $20 \%$ de sobras do oferecido, com base na ingestão do dia anterior. Para o cálculo do consumo dos nutrientes, foram pesadas e registradas a quantidade de ração oferecida e as sobras. As sobras de ração foram coletadas durante os três últimos dias de cada período experimental, sempre pela manhã. Foi retirada uma porção equivalente a $10 \%$ da sobra total durante os três dias de coleta, perfazendo amostras compostas por período. As fezes foram coletadas direto do reto do animal também nos últimos três dias de cada período para posterior formação de amostra composta por animal.

Amostras das sobras, das fezes e dos ingredientes da ração foram submetidas às análises de MS, PB EE (SILVA \& QUEIROZ, 2002), FDN (VAN SOEST et al., 1991). As amostras dos ingredientes foram ainda analisadas para cálcio, fósforo (TEDESCO, 1995), MM (SILVA \& QUEIROZ, 2002) e FDA (VAN SOEST et al., 1991). Os carboidratos não fibrosos (CNF) foram estimados utilizando a equação proposta por VAN SOEST et al. (1991), sendo a FDN corrigida para cinzas e proteína.

A análise do perfil lipídico dos óleos foi realizada por meio da preparação dos ésteres metílicos (HARA \& RADIN, 1978) e da transesterificação dos triglicerídeos (CHRISTIE, 1982) para posterior identificação e quantificação dos ácidos graxos em cromatógrafo a gás.

A energia bruta foi analisada por meio da oxidação da amostra em bomba calorimétrica tipo 'Paar', enquanto que a energia digestível (ED) foi estimada mediante a multiplicação do valor encontrado para energia bruta pela digestibilidade aparente desta (DAEB), $(\mathrm{ED}=\mathrm{EB} * \mathrm{DAEB})$. A energia metabolizável foi calculada de acordo com o NRC (1981), em que: EM = $\mathrm{ED} * 0,82$.

A digestibilidade in vitro da MS dos tratamentos experimentais (DIVMS) foi determinada por meio da metodologia de TILLEY \& TERRY, (1963). A digestibilidade dos nutrientes (MS, PB, FDN e EE) foi calculada por meio da estimativa da produção fecal e, posteriormente, da excreção fecal de cada nutriente e do consumo destes, em que: 
Consumo, digestibilidade de nutrientes e parâmetros sanguíneos de cabras mestiças moxotó...

Tabela 1 - Composição percentual e químico-bromatológica das dietas sem óleo (SO), com 3 (OL-3) e 5\% (OL-5) de óleo de licuri, 3 (OM3) e $5 \%$ (OL-5) de óleo de mamona, com base na MS.

\begin{tabular}{|c|c|c|c|c|c|}
\hline \multirow{2}{*}{ Alimentos } & \multicolumn{5}{|c|}{ 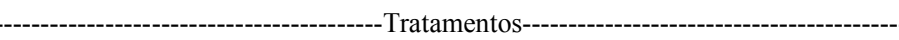 } \\
\hline & SO & $\mathrm{OL}-3$ & OL -5 & OM - 3 & OM - 5 \\
\hline Farelo de milho $^{1}$ & 25,00 & 21,00 & 18,50 & 21,00 & 18,50 \\
\hline Farelo de soja & 15,00 & 16,00 & 16,50 & 16,00 & 16,50 \\
\hline Óleo de licuri & - & 3,00 & 5,00 & - & - \\
\hline Óleo de mamona & - & - & - & 3,00 & 5,00 \\
\hline Calcário & 1,50 & 1,50 & 1,50 & 1,50 & 1,50 \\
\hline Suplemento mineral & 1,50 & 1,50 & 1,50 & 1,50 & 1,50 \\
\hline Palma forrageira & 10,00 & 10,00 & 10,00 & 10,00 & 10,00 \\
\hline Feno capim buffel & 47,00 & 47,00 & 47,00 & 47,00 & 47,00 \\
\hline \multicolumn{6}{|c|}{ Composição químico-bromatológica } \\
\hline Matéria seca & 57,20 & 57,36 & 57,46 & 57,36 & 57,46 \\
\hline Matéria mineral & 10,56 & 10,51 & 10,46 & 10,51 & 10,46 \\
\hline Proteína bruta & 11,41 & 11,46 & 11,43 & 11,46 & 11,43 \\
\hline Extrato etéreo & 3,17 & 5,80 & 7,56 & 5,80 & 7,56 \\
\hline Fibra em detergente neutro & 47,03 & 46,37 & 45,94 & 46,37 & 45,94 \\
\hline Fibra em detergente ácido & 31,88 & 31,52 & 31,29 & 31,52 & 31,29 \\
\hline Carboidratos não fibrosos & 27,60 & 25,65 & 24,34 & 25,65 & 24,34 \\
\hline Energia metabolizável $^{2}$ & 1,93 & 2,04 & 2,11 & 2,04 & 2,11 \\
\hline Cálcio & 0,99 & 0,99 & 0,99 & 0,99 & 0,99 \\
\hline Fósforo & 0,32 & 0,31 & 0,30 & 0,31 & 0,30 \\
\hline
\end{tabular}

${ }^{1}$ Subproduto da fabricação de flocos de milho.

${ }^{2}$ Mcal kg-1 de MS.

Produção Fecal $=$ CMS * $(100-$ DIVMS $) / 100$

Excreção Fecal nutriente $=$ Prod. Fecal ${ }^{*}(\%$ nutriente nas fezes) $/ 100$

Digestibilidade nutriente $=($ Consumo nutriente Excreção nutriente fezes)*100)/ Consumo nutriente

As análises foram realizadas no Laboratório de Nutrição Animal e Avaliação de Alimentos e no Laboratório de Química e Fertilidade de Solo do CCA/ UFPB.

As amostras de sangue foram obtidas nos três últimos dias de coleta, quatro horas após a alimentação matinal, por punção da veia jugular. Após a coleta, o material foi centrifugado a $3.500 \mathrm{rpm}$, por 15 minutos, e o soro resultante foi congelado a $-20^{\circ} \mathrm{C}$, para análises posteriores. As determinações das concentrações de ureia e glicose foram feitas com kits disponíveis no comércio (Labtest diagnóstica SA), empregando-se o método enzimático-colorimétrico, já a concentração de Ácidos Graxos não Esterificados (AGNE) foi determinada pelo método de JOHNSON \& PETERS (1993), utilizando-se o kit comercial teste NEFA $\mathrm{C}$ wako. Todas essas determinações foram analisadas pelo aparelho espectofotômetro.
O delineamento utilizado foi um quadrado latino duplo (5 x 5). Os dados foram compilados em planilhas eletrônicas e submetidos ao programa SAEG 7.0 (UFV, 1997). As varáveis com efeito significativo pelo teste F foram comparadas pelo teste de Tukey, a $5 \%$ de significância. O modelo estatístico utilizado na análise dos dados foi o seguinte: $Y i j k l=\mu+Q_{i}+T_{j}+P_{k}$ $+\mathrm{A}_{(\mathrm{i}) !}+\mathrm{QT}_{\mathrm{ij}}+\hat{\mathrm{i}}_{\mathrm{ijk}}$ em que: $\mu=$ efeito geral da média; $\mathrm{Q}_{\mathrm{i}}$ $=$ efeito referente ao quadrado latino $i ; T_{j}=$ efeito do tratamento $\mathrm{j} ; \mathrm{P}_{\mathrm{k}}=$ efeito do período $\mathrm{k} ; \mathrm{A}_{(\mathrm{i}) \mathrm{l}}^{\mathrm{j}}=$ efeito da cabra 1, no quadrado $\mathrm{i} ; \mathrm{QT}_{\mathrm{ij}}=$ efeito da interação quadrado latino $\mathrm{i} \times$ tratamento $\mathrm{j} ; \hat{\mathrm{i}}_{\mathrm{ijk}}=$ erro aleatório associado a cada observação Yijkl.

\section{RESULTADOS E DISCUSSÃO}

O efeito da inclusão de óleos na dieta ainda não está bem elucidado, visto que alguns autores verificaram redução no consumo (JENKINS \&THIES, 1997; SILVA et al., 2007), enquanto outros não observaram influência do lipídio na dieta (MAIA et al., 2006; LANA et al., 2007).

O óleo de Licuri é composto, em grande parte, por ácidos graxos de cadeia curta e média (predominando os ácidos caprílico (C8) - 12,15\%, láurico (C12) - 44,35\% e mirístico (C14) -13,37\%), 
provavelmente, devido a este fator foi observado o menor CMS dos animais suplementados com esse óleo (Tabela 2). De acordo com GOMES et al. (2006), não somente o grau de insaturação, mas também o tamanho da cadeia dos ácidos graxos pode afetar a fermentação ruminal e, por conseguinte, o consumo. Já o óleo de Mamona é composto em sua maioria pelo ácido graxo ricinoléico $(72,69 \%)$, que, apesar de ser um ácido graxo de cadeia longa (C18), é monoinsaturado.

GOMES et al. (2006), ao avaliar o efeito da suplementação de 2,53\% na MS com óleos de palmiste e soja na dieta de cabras leiteiras, encontraram redução no CMS quando os animais eram alimentados com óleo de palmiste. Segundo PALMQUIST \& MATTOS (2006), a redução no consumo normalmente é causada pela toxicidade do ácido graxo aos microrganismos ruminais, que está relacionada a sua natureza anfílica, isto é, aqueles que são solúveis, tanto em solventes orgânicos, quanto em água, são mais tóxicos. Tais ácidos incluem os ácidos graxos de cadeia média (de 10 a 14 átomos de carbono) e ácidos graxos poliinsaturados de cadeia longa.

Em relação ao consumo de proteína bruta (CPB) e fibra em detergente neutro (CFDN), o animais suplementados com OL-5 apresentaram menor consumo, o que pode estar relacionado com a diminuição do CMS. Já em relação à digestibilidade aparente da proteína bruta (DAPB) e digestibilidade da fibra em detergente neutro (DFDN), os animais submetidos à dieta controle ( $\mathrm{SO}$ ) apresentaram menores valores em relação aos demais tratamentos. De acordo com WALDO e colaboradores em 1972, citados por POPPI et al. (2000), existe uma interação entre consumo, digestibilidade e taxa de passagem. Logo, é de se esperar que qualquer tratamento que modifique o consumo consequentemente alterará a taxa de passagem e, por conseguinte, a digestibilidade dos nutrientes, como aconteceu com a DAPB e DFDN. Além disso, em relação à DFDN, HUSSEIN et al. (1995) afirmam que altas concentrações de fibra na dieta promovem condições para o crescimento acelerado de microrganismos que são os responsáveis pela hidrólise e hidrogenação da gordura dietética.

PALMQUIST \& MATTOS (2006) afirmam que ácidos graxos associam-se com as superfícies hidrofóbicas das partículas de alimento, o que explica a baixa toxicidade das gorduras quando o animal é alimentado com rações mais ricas em volumosos. Em todos os tratamentos deste estudo, há uma grande participação de volumoso ( $47 \%$ de feno na MS) na dieta. Outros fatores, como alto teor de minerais, em especial o cálcio, também minimizam o efeito negativo da adição de lipídeos (NÖRNBERG et al., 2004).

NÖRNBERG et al. (2004) mencionam ainda que a variação da digestibilidade da MS e de nutrientes depende dos seguintes fatores: nível relativamente

Tabela 2 - Médias e coeficiente de variação (CV \%) para consumo e digestibilidade dos nutrientes de acordo com as dietas experimentais.

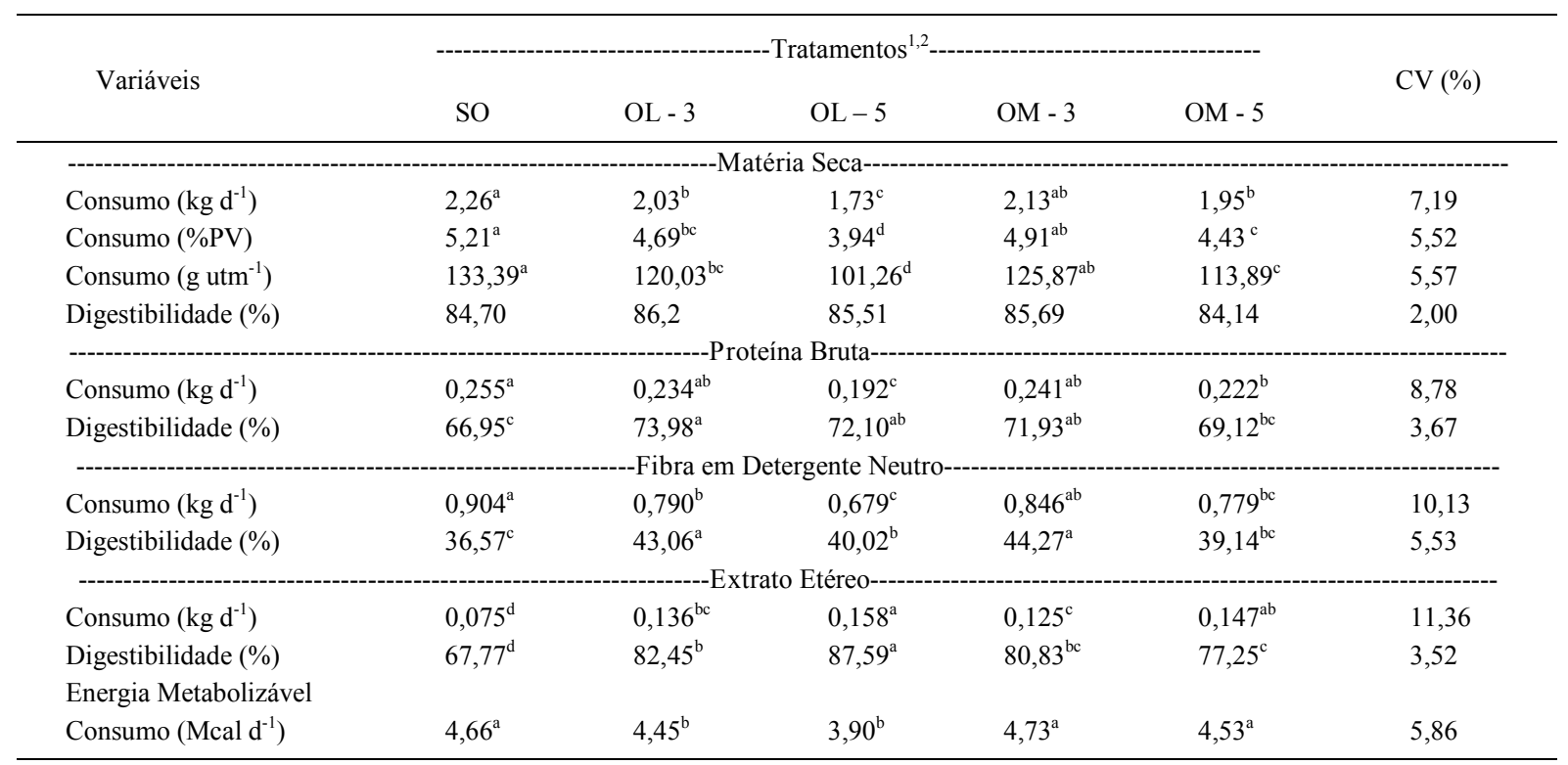

${ }^{1}$ SO - sem óleo na dieta; OL - 3: adição de 3\% de óleo de licuri na MS da dieta; OL - 5: adição de 5\% de óleo de licuri na MS da dieta ; OM3: adição de 3\% de óleo de mamona na MS da dieta ; OM - 5: adição de 5\% de óleo de mamona na MS da dieta.

${ }^{2}$ Médias seguidas de letras diferentes na mesma linha diferem até $5 \%$ de significância, pelo teste de Tukey. 
baixo de gordura na dieta basal ( $3,17 \%$ neste estudo); fontes de gordura com ácidos graxos na forma esterificada (triglicerídeos); quantidade de ácidos graxos insaturados condizentes com a capacidade de hidrogenação dos microrganismos no rúmen; níveis adequados de FDN (acima de $45 \%$ em todos os tratamentos $)$ e de cálcio $(0,99 \%$ na MS $)$ das dietas. Um ou mais desses fatores podem ter contribuído de forma isolada ou conjunta.

Em relação ao consumo de energia metabolizável (CEM), a inclusão de óleo de Licuri reduziu o consumo em relação aos demais tratamentos, provavelmente devido ao menor CMS dos animais que se encontravam nesses tratamentos.

Já em relação ao consumo de extrato etéreo (CEE), a suplementação lipídica proporcionou CEE superiores ao da dieta controle, o que era esperado, pois as dietas foram formuladas com contribuição do EE suplementar de 2,63 e 4,39\% para as dietas com 3 e $5 \%$ de óleo, respectivamente.

Em se tratando da digestibilidade aparente do extrato etéreo (DAEE), notou-se redução quando os animais eram alimentados com a dieta controle e aumento quando os animais consumiam óleo de Licuri ou Mamona e, principalmente, no que diz respeito à adição de 5\% de Licuri, estando de acordo com a literatura que indica efeito positivo na digestibilidade do EE, com o incremento de lipídeos na dieta.

No presente estudo, não foi verificada diferença entre os tratamentos em relação às concentrações $\left(\mathrm{mmol} \mathrm{L}^{-1}\right)$ de ureia, glicose e ácidos graxos não esterificados (AGNE) no sangue de cabras em lactação (Tabela 3).

Geralmente, alterações na concentração de ureia estão correlacionadas com o conteúdo de amônia ruminal cuja utilização depende da atividade metabólica dos microrganismos ruminais. Estes transformam o nitrogênio da amônia em proteína bacteriana, processo que requer energia. Logo, se a ração estiver deficiente em energia prontamente disponível, as concentrações de amônia aumentam no rúmen, e a quantidade de ureia aumenta no sangue (CONTRERAS et al., 2000). Sendo assim, a concentração de ureia sanguínea está diretamente correlacionada com o teor de proteína na dieta, o aporte energético da ração e a interação entre esses fatores. Neste estudo, apesar de ter ocorrido uma diminuição no CPB dos animais alimentados com óleo de Licuri, as dietas eram isonitrogenadas, por este motivo, provavelmente, não houve diferença na concentração de ureia no sangue dos animais. CONTRERAS et al. (2000) citam que os valores de referência para ureia em caprinos se situam entre $2,0 \mathrm{e}$ $8,0 \mathrm{mmol} \mathrm{L}^{-1}$, estando os valores encontrados dentro dos padrões.

Em relação à concentração de glicose sanguínea, segundo GAGLIOSTRO \& CHILLIARD (1992), diversos mecanismos de economia desse metabólito pelo organismo dos ruminantes podem explicar a manutenção da glicemia apesar da redução no consumo de MS, que ocorre muito frequentemente ao utilizar-se a suplementação lipídica.

Elevadas concentrações de AGNE no plasma são usadas para indicar a mobilização de gordura durante período de insuficiente consumo de energia, resultando em lipólise do tecido adiposo (ERICKSON et al., 1992). Neste estudo, não foi observada alteração no nível de AGNE, indicando que não houve mobilização de gordura corporal.

Os resultados da concentração de AGNE plasmático encontrados em animais suplementados com lipídeos são bastante variados. A literatura mundial apresenta vários trabalhos em que a adição de gordura provocou um aumento na concentração do AGNE sanguíneo (BERTICS \& GRUMMER, 1999; AVILA et al., 2000). Entretanto, outros autores não verificaram alteração no teor desse metabólito no sangue (PIRES et al., 1996; BERMUDES et al., 2003).

Tabela 3 - Médias e coeficiente de variação $(\mathrm{CV})$ para metabólitos $\left(\mathrm{mmol} \mathrm{L}^{-1}\right)$ sanguíneos de cabras mestiças Moxotó alimentadas com dieta sem suplementação lipídica (SO) e suplementadas com óleo de licuri (OL) ou óleo de mamona (OM) nos níveis de 3 e 5\% na matéria seca.

\begin{tabular}{llccccc}
\hline & & & & \\
Variáveis (\%) & SO & OL - 3 & OL - 5 & OM - 3 & OM - 5 \\
\hline Ureia & 7,65 & 7,59 & 7,69 & 7,46 & 7,80 \\
Glicose & 2,38 & 2,33 & 2,25 & 2,43 & 2,31 \\
AGNE $^{2}$ & 156,58 & 178,10 & 181,32 & 167,06 & 167,44 \\
\hline
\end{tabular}

\footnotetext{
${ }^{1}$ Médias seguidas de letras diferentes na mesma linha diferem até 5\% de significância, pelo teste de Tukey.

2 Ácidos graxos não esterificados.
} 


\section{CONCLUSÃO}

Entre os tipos e níveis de óleos estudados, apesar de não haver diferença para a digestibilidade dos nutrientes e os parâmetros sanguíneos, a adição de 3\% de óleo de Mamona promoveu maior consumo, não diferindo da dieta controle e podendo ser adicionado à dieta de cabras no período da lactação.

\section{AGRADECIMENTO}

Ao Banco do Nordeste do Brasil pelo suporte financeiro concedido para realização deste trabalho.

\section{REFERÊNCIAS}

AVILA, C.D. et al. Influences of saturation ratio of supplemental dietary fat on digestion and milk yield in dairy cows. Journal of Dairy Science, v.83, n.7, p.1505-1519, 2000. Disponível em: <http://jds.fass.org/cgi/reprint/83/7/1505>. Acesso em: 15 dez. 2008 .

BERMUDES, R.F. et al. Gordura protegida na dieta de vacas de alta produção a campo, em alfafa verde ou pré-secada, na fase inicial da lactação: Parâmetros plasmáticos. Revista Brasileira de Zootecnia, v.32, n.2, p.405-410, 2003. Disponível em: <http:/ /dx.doi.org/10.1590/S1516-35982003000200019>. Acesso em: 15 out. 2008. doi: 10.1590/S1516-35982003000200019.

BERTICS, S.J.; GRUMMER, R.R. Effects of fat and methionine hydroxy analog on prevention or alleviation of fatty liver induced by feed restriction. Journal of Dairy Science, v.82, p.2731-2736, 1999. Disponível em: <http://jds.fass.org/cgi/ reprint/82/12/2731>. Acesso em: $10 \mathrm{dez} .2008$.

CONTRERAS, P.A. et al. Uso dos perfis metabólicos no monitoramento nutricional dos ovinos. In: GONZÁLEZ, F.H.D. et al. (Ed.). Perfil metabólico em ruminantes: seu uso em nutrição e doenças nutricionais. Porto Alegre: Universidade Federal do Rio Grande do Sul, 2000. p.75-88.

CREPALDI, I.C. et al. Composição nutricional do fruto de licuri (Syagrus coronata (Martius) Beccari). Revista Brasileira de Botânica, v.24, p.155-159, 2001. Disponível em: <http:// dx.doi.org/10.1590/S0100-84042001000200004>. Acesso em: 5 dez. 2008. doi: 10.1590/S0100-84042001000200004.

CHRISTIE, W.W. A simple procedure for rapid transmethilation of glycerolipids and cholesterol esters. Journal of Lipid Research, n.23, p.1072-1075, 1982. Disponível em: <http:/ /www.jlr.org/cgi/reprint/23/7/1072>. Acesso em: 12 nov. 2008.

ERICKSON, P.S. et al. Supplementation of dairy cow diets with calcium salts of long-chain fatty acids and nicotinic acid in early lactation. Journal of Dairy Science, v.75, p.10781089, 1992. Disponível em: <http://jds.fass.org/cgi/reprint/ 75/4/1078>. Acesso em: 3 out. 2008.

GAGLiOSTRO, G.A.; CHILliARD, Y. Utilización de lípidos protegidos en la nutrición de vacas lecheras. II. Efectos sobre la concentración plasmática de metabolitos y hormonas, movilización de lípidos corporales y actividad metabólica del tejido adiposo. Revista Argentina de Producción Animal, v.12, p.17-32, 1992.
GOMES, G.M.F. et al. Consumo, produção e constituintes lácteos de cabras leiteiras alimentadas com diferentes fontes de óleo. In: REUNIÃO ANUAL DA SOCIEDADE BRASILEIRA DE ZOOTECNIA, 43., 2006, João Pessoa. Anais... João Pessoa: SBZ, 2006. (CD-ROM).

HARA, A.; RADIN, N.S. Lipid extraction of tissues with lowtoxicity solvent. Analytical Biochemistry, v.90, p.420-426, 1978. Disponível em: http://dx.doi.org/10.1016/00032697(78)90046-5. Acesso em: 2 out. 2008. doi: 10.1016/ 0003-2697(78)90046-5.

HUSSEIN, H.S. et al. Effects of forage level and canola seed supplementation on site and extent of digestion of organic matter, carbohydrates, and energy by steers. Journal of Animal Science, v.73, p.:2458-2468, 1995. Disponível em: <http://jas.fass.org/cgi/reprint/ 73/8/2458 maxtoshow $=\&$ HITS $=10 \&$ hits $=10 \&$ RESULTFORM $\mathrm{AT}=\&$ author $1=$ Hussein $\&$ andorexactitle $=$ and $\&$ and orexacttitleabs =and \& andorexactfulltext $=a n d$ $\&$ searchid $=1 \&$ FIRSTINDEX $=0$ \&sortspec $=$ relevance $\&$ volume $=73$ $\&$ firstpage $=2458 \&$ resourcetype $=$ HWCIT $>$. Acesso em: 10 nov. 2008.

JOHNSON, M.M.; PETERS, J.P. Technical note: an improved method to quantify nonesterified fatty acids in bovine plasma. Journal of Animal Science, v.71, p.753-756, 1993. Disponível em: <http://jas.fass.org/cgi/ reprint $/ 71 / 3 / 753$ ? maxtoshow $=\&$ HITS $=10 \&$ hits $=10 \&$ RESUL T F O R M A T = \& a u t h o r $1=\mathrm{J} \mathrm{O} \mathrm{H} \mathrm{N} \mathrm{S} \mathrm{O} \mathrm{N}$ $\&$ andorexacttitle $=$ and $\&$ andorexacttitleabs $=$ and \& a ndorexactfulltext=and \& s e a r c hid $=1 \&$ FIR S T I N D E X $=0 \&$ s o r t s p e c $=$ re 1 e v a n c e $\&$ v o 1 u me $=71 \&$ firstpage $=753 \&$ resourcetype $=$ HWCIT>. Acesso em: 5 nov. 2008.

LANA, R.P. et al. Óleo de soja e própolis na alimentação de cabras leiteiras: consumo de matéria seca e de nutrientes e parâmetros de fermentação ruminal. Revista Brasileira de Zootecnia, v.36, p.191-197, 2007. Disponível em: <http:// dx.doi.org/10.1590/S1516-35982007000100023>. Acesso em: 29 set. 008. doi: 10.1590/S1516-35982007000100023.

MAIA, F.J. et al. Inclusão de fontes de óleo na dieta de cabras em lactação: digestibilidade dos nutrientes e parâmetros ruminais e sangüíneos. Revista Brasileira de Zootecnia, v.35, p.14961503, 2006. Disponível em: < http://dx.doi.org/10.1590/S151635982006000500032>. Acesso em: 15 set. 2008. doi: 10.1590/ S1516-35982006000500032.

NÖRNBERG, J.L. et al. Valor do farelo de arroz integral como fonte de gordura na dieta de vacas jersey na fase inicial de lactação: digestibilidade aparente de nutrientes. Revista Brasileira de Zootecnia, v.33, p.2412-2421, 2004. Disponível em: <http:// www.scielo.br/scielo.php? script $=$ sci_arttext\&pid $=\mathrm{S} 15165982004000900030 \& \operatorname{lng}=\mathrm{pt} \& \mathrm{nrm}=\mathrm{iso}>$. Acesso em: 12 out. 2008.

NRC - NATIONAL RESERARCH COUNCIL. Nutrient requirement of dairy goats. Washington: Nat. Academic, 1981. 110p.

NRC - NACIONAL RESEARCH COUNCIL. Nutrient requirements of small ruminants. Washington: Nat. Academic, 2007. 384p.

OLIVEIRA, S.G. et al. Principais aspectos relacionados às alterações no perfil de ácidos graxos na gordura do leite de ruminantes. Arquives of Veterinary Science, v.9, p.73-80, 2004. Disponível em: <http://ojs.c3sl.ufpr.br/ojs2/index.php/ veterinary/article/view/4049/3280>. Acesso em: 3 out. 2008. 
PALMQUIST, D.L.; MATTOS, W.R.S. Metabolismo de lipídeos. In: BERCHIELLI, T.T. et al. Nutrição de ruminantes. Jaboticabal: FUNEP, 2006. Cap.10, p.287-310.

PIRES, A.V. et al. Roasted soybeans, blood meal, and tallow as sources of fat and ruminally undegradable protein in the diets of lactating cows. Journal of Dairy Science, v.79, p.16031610, 1996. Disponível em: <http://jds.fass.org/cgi/reprint/ 79/9/1603>. Acesso em: 3 out. 2008.

POPPI, D.P. et al. Intake, passage and digestibility. In: THEODOURO, M.K.; FRANCE, J. (Eds.). Feed systems and feed evaluation models. New York: CAB International, 2000. p.35-52.

SEVERINO, L.S. O que sabemos sobre a torta de mamona Campina Grande, PB.: Embrapa Algodão, 2005. 31p.il. (Documentos), 134.

SILVA, D.J.; QUEIROZ, A.C. Análises de alimentos: métodos químicos e biológicos. Viçosa/MG: UFV, 2002. 235p. il.

SILVA, M.M.C. et al. Suplementação de lipídios em dietas para cabras em lactação: consumo e eficiência de utilização de nutrientes. Revista Brasileira de Zootecnia, v.36, p.257267, 2007. Disponível em: <http://dx.doi.org/10.1590/S1516-
35982007000100030>. Acesso em: 12 out. 2008. doi: 10.1590/S1516-35982007000100030.

TEDESCO, M.J. Análise de solo, planta e outros materiais. 2.ed. Porto Alegre: UFRGS, 1995. 174 p. il. (Boletim Técnico, n.5).

TILLEY, J.A.; TERRY, A.R. A two-stage technique for in vitro digestion of forages crops. Journal of the British Grassland Society, v.18, p.104-111, 1963. Disponível em: <http:// dx.doi.org/10.1111/j.1365-2494.1963.tb00335.x>. Acesso em: 2 out. 2008 . doi: 10.1111/j.1365-2494.1963.tb00335.x.

UNIVERSIDADE FEDERAL DE VICCOSA - UFV. SAEG Sistema para análises estatísticas e genéticas. Versão 7.1. Viçosa, MG, 1997. 150p. (Manual do usuário). Disponível em: http://www.ufv.br/saeg. Acesso em: 5 set. 2008.

VAN SOEST, P.J. et al. Methods for extraction fiber: neutral detergent fiber and nonstarch polyssacarides in relation animal nutrition. Journal of Dairy Science, v.83, n.1, p.35833597, 1991. Disponível em: <http://jds.fass.org/cgi/reprint/ 74/10/3583>. Acesso em: 2 out. 2008.

VIEIRA, R. de M. et al. Competição de cultivares e linhagens de mamoneira no Nordeste do Brasil- 1993/ 96. Campina Grande: EMBRAPA-CNPA, 1998. 4p. (Comunicado tecnico, 71). 